\title{
J.-F. Marmontel, Les Incas, ou la destruction de
} l'Empire du Pérou

\section{Vittorio Fortunati}

\section{(2) OpenEdition \\ 1 Journals}

\section{Edizione digitale}

URL: http://journals.openedition.org/studifrancesi/9965

DOI: 10.4000/studifrancesi.9965

ISSN: 2421-5856

\section{Editore}

Rosenberg \& Sellier

\section{Edizione cartacea}

Data di pubblicazione: 1 août 2017

Paginazione: 361

ISSN: 0039-2944

\section{Notizia bibliografica digitale}

Vittorio Fortunati, «J.-F. Marmontel, Les Incas, ou la destruction de l'Empire du Pérou», Studi Francesi

[Online], 182 (LXI | II) | 2017, online dal 01 août 2017, consultato il 06 janvier 2021. URL: http:// journals.openedition.org/studifrancesi/9965 ; DOI: https://doi.org/10.4000/studifrancesi.9965

Questo documento è stato generato automaticamente il 6 janvier 2021.

\section{(c) (i) $\odot$}

Studi Francesi è distribuita con Licenza Creative Commons Attribuzione - Non commerciale - Non opere derivate 4.0 Internazionale. 


\title{
J.-F. Marmontel, Les Incas, ou la destruction de l'Empire du Pérou
}

\author{
Vittorio Fortunati
}

\section{NOTIZIA}

JEAN-FRANÇOIS MARMONTEL, Les Incas, ou la destruction de l'Empire du Pérou, texte établi et présenté par Pierino Gallo, Paris, Société des Textes Français Modernes, 2016, 629 pp.

1 Non sempre la fortuna critica di un autore è direttamente proporzionale alla sua importanza storica. Gli studi su Jean-François Marmontel sono ancora, quantitativamente, modesti rispetto all'abbondanza e alla varietà della sua produzione letteraria, e al successo che essa riscosse tra i contemporanei. Un caso esemplare è rappresentato da Les Incas, ou la destruction de l'Empire du Pérou: pubblicata per la prima volta nel 1777, tradotta in diverse lingue e rimasta in auge fino a buona parte dell'Ottocento, quest'opera non ha conosciuto edizioni moderne fino a quella di cui oggi rendiamo conto, che si caratterizza per l'accuratezza filologica e per la ricchezza delle note esplicative.

2 Les Incas descrive la conquista del Perù da parte delle truppe di Francisco Pizarro tra il 1532 e il 1533: un'impresa militare che ampliò i già vasti domini spagnoli nel Nuovo Mondo, ma che nello stesso tempo causò la fine di una delle più fiorenti civiltà precolombiane e lo sterminio di parte della popolazione indigena. Sono, in effetti, gli aspetti meno onorevoli della conquista e le sue tragiche conseguenze ad essere messi in maggiore evidenza dall'autore, sulla scorta delle sue fonti storiche: in particolare la Brevísima relación de la destruyción de las Indias del gesuita Bartolomé de Las Casas, ma anche i Comentarios reales de los Incas di Garcilaso de La Vega e l'Histoire des deux Indes dell'abbé Raynal.

3 Nel suo Essai sur les romans considérés du côté moral (1778), Marmontel descrisse, con la denominazione di «roman politique», quello che potremmo definire romanzo storico: Les Incas ne è un esempio nella misura in cui fatti e personaggi sono in gran parte reali; 
in esso si fondono tuttavia gli influssi di altri generi letterari. Dall'epopea, per esempio, derivano le descrizioni delle battaglie e degli eserciti schierati in campo (qui il modello è soprattutto la Farsalia di Lucano) e le complesse similitudini. Dal romanzo eroico provengono i racconti retrospettivi, grazie ai quali sono narrate la conquista del Messico da parte di Cortés, l'origine dell'impero Inca e la nascita dell'Inquisizione spagnola. Sono, invece, riconducibili al romanzo sentimentale le scene patetiche e, soprattutto, la storia d'amore fra lo spagnolo Alonzo e la peruviana Cora, vergine consacrata al culto del Sole. Il modello letterario principale è, però, il Télémaque di Fénelon, sia per il carattere "poetico", cioè armonioso e ritmato, della prosa, che per l'intento dichiaratamente edificante.

4 Il messaggio morale e ideologico de Les Incas è, infatti, esplicitato dal suo autore nella Préface (pp. 85-102): l'asservimento dei popoli andini fu dovuto, indubbiamente, all'avidità dei conquistadores, ma esso, secondo Marmontel, assunse caratteri di particolare atrocità soprattutto a causa del fanatismo religioso, della pretesa di imporre la propria fede con qualunque mezzo. L'atteggiamento dei personaggi nei confronti della diversità religiosa e culturale li divide, se così si può dire, in "buoni" e "cattivi": tra i primi vanno citati l'anziano padre Las Casas, l'apostolo delle Indie che denunciò il genocidio dei nativi, e il giovane Alonzo, spinto dalla coscienza (e dall'amore) a unirsi al popolo che era venuto a combattere; tra gli altri spicca il losco Valverde, frate vizioso e ipocrita, che aizza gli spagnoli allo sterminio degli "infedeli". Quanto a Francisco Pizarro, il narratore lo descrive come un uomo ambizioso ma onesto, che fu travolto dagli eventi anche perché circondato da persone infide. Nella sua Préface Marmontel si premura di distinguere il fanatismo dalla vera fede; in effetti, i discorsi religiosi presenti nel testo (quelli, naturalmente, pronunciati dai personaggi positivi) hanno un contenuto più deista che cristiano: anche sotto questo aspetto, Les Incas è un prodotto esemplare del secolo dei Lumi. 